\title{
LA ORTOGRAFÍA ESPAÑOLA Y SU DIDÁCTICA EN LA EDUCACIÓN GENERAL BÁSICA
}

\author{
Marielos Murillo Rojas*
}

\begin{abstract}
RESUMEN
El presente artículo tiene como propósito presentar el recorrido histórico de la enseñanza de la ortografía en Costa Rica, de 1909 al 2012 y algunas características generales sobre de la competencia ortográfica del escolar costarricense. Además, se analizan las estrategias didácticas para la enseñanza ortografía española y se presenta una propuesta de programación del aprendizaje ortográfico en la escuela primaria costarricense, por año escolar.

Palabras clave: Lengua, enseñanza de la ortografía, educación primaria, programación curricular.
\end{abstract}

\begin{abstract}
$\operatorname{ABSTRACT} * *$
This article presents the historical background of spelling teaching in Costa Rica from 1909 to 2012. Furthermore, it focuses on some general characteristics of spelling competence in Costa Rican children. We also analyze some Spanish spelling teaching strategies and propose a model regarding orthographic learning for elementary schools in Costa Rica.

Key Words: language, spelling teaching, elementary education, curricular plan.
\end{abstract}

\section{Introducción}

La ortografía ha sido siempre motivo de preocupación de los académicos y educadores; prueba de ello es que a partir de la primera edición de la ortografía del español en 1741, ha continuado una serie de publicaciones posteriores, muchas de ellas con adecuaciones paralelas a la evolución de nuestra lengua como producto histórico social compartido por hablantes hispanoamericanos, peninsulares, guineanos y filipinos.

Lograr que el alumno escriba con ortografía requiere conocer vocabulario básico que usa al escribir, cuáles son las palabras que producen mayor número de errores y si los estudiantes aplican patrones sistemáticos que orienten la intervención pedagógica al trabajar grupos de palabras.

Es oportuno tener en cuenta que la enseñanza de la ortografía presenta tres dimensiones: una, lingüística, relativa a la caracterización del sistema ortográfico en la representación escrita del lenguaje; otra, psicológica, relativa a los procesos cognitivos involucrados en el aprendizaje escrito, en general, y en la convencionalidad ortográfica, en

\footnotetext{
* $\quad$ Profesora, Escuela de Formación Docente. Universidad de Costa Rica.

** Traducción: Licda. Geannette Soto. Escuela de Lenguas Modernas. Universidad de Costa Rica. Recepción:14/03/13. Aceptación: 01/04/13.
} 
particular; y, la última, pedagógica, que supone la revisión crítica de los modelos vigentes de intervención educativa y la transformación de las estrategias pedagógicas en el dominio ortográfico (Cfr. Matteoda y Vázquez, 1997).

Adicionalmente es fundamental tener presente que el dominio ortográfico guarda relación con el nivel cronológico y madurativo; en un primer momento, se exige una ortografía natural, que consiste en identificar cada signo fónico con su equivalente gráfico y la separación de las palabras dentro de la frase; después, el uso de una ortografía apegada a la normativa de la lengua. Esta última debe responder a una programación fundamentada en las dificultades de representación del código escrito y en el comportamiento y desarrollo del educando. En este sentido los programas no deben repetir las listas de reglas ortográficas sin que medie ningún criterio sustentado en la producción textual del escolar.

\section{La enseñanza de la ortografía en la educación primaria costarricense. Período 1907-2012}

En vista de la escasez documental y pruebas testimoniales acerca de la enseñanza de la lengua española durante gran parte del siglo $\mathrm{XX}$, nos abocaremos, fundamentalmente, al estudio de los programas de educación primaria emitidos en 1909, 1926, 1936, 1941, 1962, 1969 , 1972, 1974, 1977, 1980, 1987, 1991, 1995, 2001 y 2005. Además de otros documentos que orientaron la enseñanza del Español, durante el período estudiado.

Con el propósito de organizar la información se considerarán las tendencias generales que han marcado cambios o transiciones en la evolución de la enseñanza de la lengua en la educación primaria costarricense, con especial atención al código escrito y particularmente la enseñanza ortografía.

1909. En el Programa de instrucción pública, 1909, se trabajaba la composición muy ligada a la escritura de textos narrativos, descriptivos, el resumen y la escritura de cartas, avisos, recibos, etc. La copia, el dictado, la composición colectiva figuran como estrategias para el desarrollo de la expresión escrita.

El estudio de la puntuación y la ortografía acompañan al niño durante toda la escolaridad, pero, por ventura, no aparecen detalladas reglas ortográficas por grado, excepto las reglas del acento que se incluyen específicamente en tercer grado.

La gramática como objeto de estudio aparece en cuarto grado y se refuerza en quinto grado, a tal punto que el programa es básicamente el desarrollo de temas gramaticales.

1926. En 1926, se publican los programas oficiales de instrucción primaria, la "Lengua Materna queda como necesaria en todas las asignaturas, ya que debe ser la expresión fiel y correcta de nuestras ideas en todas y cada una de las ciencias" (p.3).

El programa de lengua materna se organiza en cinco áreas independientes, los cuales hacen referencia a las metas por lograr, algunas propuestas metodológicas y actividades recomendadas.

En este programa se explicita la preocupación de los educadores por la escritura correcta de las palabras y el elevado valor e importancia que se le atribuye. La puntualización de las reglas ortográficas por nivel contrasta con el programa anterior, el cual hacía mención a la importancia de la escritura correcta de las palabras, pero no señalaba contenidos ortográficos específicos.

Esta nueva respuesta, sin duda muy bien intencionada, recargó el nuevo programa de reglas ortográficas, sin considerar la correspondencia entre dominio ortográfico y nivel cronológico y madurativo del escolar.

Respecto de las estrategias metodológicas y actividades se encuentra una combinación entre el dictado, las copias y los ejercicios de pronunciación. Además, se señala explícitamente, en el programa de primer grado, el procedimiento para trabajar la copia y el dictado.

De segundo a sexto grados, la enseñanza de la ortografía se reduce al estudio de reglas 
ortográficas, seguidas de los procedimientos recomendados para su introducción: en segundo grado se estudian seis reglas ortográficas; en tercer grado se adicionan siete reglas ortográficas más a las existentes; en cuarto grado se agregan nueve reglas ortográficas; en quinto grado se repasan las reglas ortográficas estudiadas hasta el momento y se añaden otras siete; en sexto grado se repasan todas las reglas estudiadas los años anteriores.

La corrección ortográfica es tarea integrada a toda actividad de escritura, a fin de evitar que el alumno corrija sus errores de forma inmediata.

Si bien, en este programa se insiste en que la gramática no se estudia separadamente, se considera indispensable sintetizar observaciones sobre el lenguaje en los distintos grados, tanto porque unos conocimientos están basados en otros, como porque el aprendizaje de idiomas lo requiere.

Ahora bien, a tono con el concepto de lengua vigente en aquel momento se habla de "vicios del lenguaje", los cuales deben evitarse, en primera instancia, mediante una pronunciación normativa. Por tanto, la corrección de la lengua oral forma parte del programa de gramática.

Para el estudio del vocabulario se recomienda como obra de referencia el libro "Vocabulario de los Niños" del maestro Carlos Gagini (1897), el cual facilitaría el estudio de familias de palabras, de los homónimos, parónimos, sinónimos y antónimos más frecuentes.

Este programa es bastante extenso, pese a que se señala repetidamente que se ha entresacado apenas lo indispensable para promover la buena expresión y la buena ortografía. Además, se ocupaba fundamentalmente de los aspectos formales de la escritura y no de los procesos de producción textual.

Tal como señalara la Dra. Emma Gamboa (1979) este programa es básicamente una puntualización de contenidos y en nuestro caso principalmente en lo referente a la enseñanza de la ortografía y de la gramática.
1936. Por su parte el programa de educación primaria de 1936 consta de listas de temas o asuntos para ser enseñados con una introducción que desarrolla algunas consideraciones pedagógicas. El programa de lengua materna se organiza en cuatro apartados: lectura, escritura (caligrafía y dictado), lenguaje (expresión oral y escrita) y memorización.

Consideramos, al igual que la Dra. Emma Gamboa (1979) que este programa no constituyó ningún avance en el desarrollo y crecimiento de la educación primaria en Costa Rica y repite en igual medida la puntualización temática de las áreas de gramática y de ortografía del programa anterior.

1941. El programa de 1941 especifica que la enseñanza de la lengua materna debe ser esencialmente práctica: "nada de clasificaciones, nada de definiciones, sino el pensar correcto manifestado a través de una frase lo más correcta posible. Y eso se obtiene con la lectura inteligente, con la apreciación de lo que los demás han escrito y con la expresión correcta de lo que el niño desea comunicar a los demás. Mucha lectura, ejercicios constantes de expresión, tanto oral como escrita, dando sin embargo predominio a la primera" (p.5).

Es destacable el cambio que experimenta la enseñanza de la ortografía respecto del programa anterior, el cual acogió la enseñanza de reglas ortográficas como mecanismo para lograr una escritura correcta de palabras y textos. El programa actual (1941), sin duda, representa una evolución en este aspecto, pues sustituye las reglas por una recomendación teórico-metodológica:

De la lectura se obtendrán las observaciones
ortográficas más sencillas, las cualeshandehacerse
valiéndose de las cuatro memorias diferentes
que posee el niño: la visual, (presentación en la
pizarra), la auditiva, (pronunciación correcta por
el maestro) y la cinética de la mano (escritura
correcta por el alumno). Este método ha de
aplicarse en todos los años (p. 10).

1962. Dos décadas después en 1962 se plantea una nueva política educativa integral, la cual contempla una reforma a la organización de 
la escuela primaria rural, a fin de abarcar los seis grados escolares. Se reimprime el plan de estudio para las escuelas primarias, el cual presenta leves modificaciones respecto del anterior: se incluyen los fines de la educación primaria; del fundamento pedagógico se suprimen los puntos referidos al método Decroly y al método idiovisual de lectura; los conocimientos mínimos por año escolar también experimentan un reacomodo.

En la edición de 1962 se revisan y redistribuyen los criterios de aprobación en el área de lengua materna:

De primer a segundo grado: "Lectura de las palabras y de las frases vistas durante el año, excluyendo combinaciones. Escritura al dictado de palabras y de frases vistas durante el año. En ortografía se exigirá un 20 por ciento de la corrección en el dictado. Escritura de cantidades hasta 20".

De segundo a tercer grado. "Lectura de cualquier clase de palabras corriente. Explicación oral de una lectura fácil, tomada del libro de lecturas usado en el curso. Escritura, al dictado, de un trozo fácil. En ese dictado se exigirá un 25 por ciento de corrección ortográfica. Composiciones orales de tema sencillo".

De tercero a cuarto grado: "Lectura de trozos de mediana dificultad. Resúmenes orales de lectura silenciosa hecha en trozos que estén al alcance de las inteligencias infantiles de este grado. Escritura al dictado de trozos adecuados. En estos dictados se exigirá el 30 por ciento de corrección ortográfica".

De cuarto a quinto grado: "Lectura de trozos de dificultad mediana. Resúmenes orales de lectura silenciosa. En ortografía se exigirá un 40 por ciento de corrección en dictados apropiados. Reconocimiento de sustantivos y de adjetivos."

De quinto a sexto grado: "Lectura silenciosa controlada con resúmenes orales o escritos.

Redacción de correspondencia familiar sencilla. En ortografía se exigirá un 50 por ciento de corrección en dictados apropiados."

Al concluir la escolaridad primaria: "Saber leer corrientemente y darse cuenta de lo que se lee; saber expresar con relativa corrección lo que conoce de cualquier asunto y saber redactar cartas y documentos sencillos (60 por ciento de corrección ortográfica)".

En términos generales, los aspectos considerados para la aprobación son la lectura, la escritura (al dictado, redacción de correspondencia familiar), la ortografía y la expresión oral (explicación oral y el resumen de textos leídos), todos valorados según criterio del educador, pues, dichosamente, no se ofrecen parámetros cuantitativos, excepto para el rendimiento en ortografía.

1969. Se consultó un ejemplar incompleto, el cual constaba de una presentación, el acta de aprobación del programa, emitida por Consejo Superior de Educación, el programa correspondiente a primer grado de las cuatro asignaturas básicas y los objetivos por desarrollar en el área de lengua durante educación primaria Un aspecto por destacar es la inclusión de la escucha atencional como objeto de enseñanza y aprendizaje, de esta forma se va perfilando un estudio de la lengua desde una perspectiva más integral y se vislumbra un acercamiento al desarrollo de las habilidades comunicativas de los educandos.

1974. Este programa fue emitido en el marco del Plan Nacional de Desarrollo Educativo (PNDE), 1970-1974, el cual contempló entre sus metas: elevar el nivel educativo promedio de la población; poner al alcance de todos los ciudadanos una educación general básica de nueve años; modernizar el sistema educativo, reorganizando el currículo en cuanto a contenidos y métodos e introduciendo el aprestamiento tecnológico (cfr. Dengo, 1995).

Únicamente se logró localizar el programa de Español de primer ciclo. Un aspecto de forma por resaltar es que este es el primer programa que presenta las áreas instrumentales -Matemáticas, Español, Ciencias y Estudios Sociales- en folletos separados, los precedentes se diseñaron por asignaturas, pero en un mismo documento.

Se agrega que la preocupación fundamental de primer ciclo es enseñar al niño los aspectos fundamentales de la lectura y la 
escritura y que se recomienda un adecuado apretamiento. También se pone énfasis en el desarrollo de habilidades para la expresión oral y la escucha, además del reconocimiento contextual de los elementos gramaticales.

En términos generales, la visión de la enseñanza del español es un poco más amplia, pues se incorpora al alumno como elemento fundamental del proceso de aprendizaje, se integran las cuatro habilidades lingüísticas hablar, escuchar, leer y escribir-, se propone el desarrollo de una actitud crítica y creadora como parte del desarrollo de las habilidades lingüístico-comunicativas de la persona. No obstante, continúan con la tradición heredada de focalizar la escritura en aspectos ortográficos y gramaticales.

Esta propuesta se concreta a presentar un listado de contenidos, muchos de los cuales no se reflejan en los objetivos específicos propuestos para este ciclo, debilidad que se acrecienta al carecer cada grado de perfiles de salida. Un aspecto que vale la pena rescatar es el tratamiento que se da a la ortografía, afortunadamente no se enumeran reglas, sino que se acude al dictado a fin de fijar el vocabulario básico graduado que se va incorporando año tras año. Además, en tercer grado se recomienda realizar ejercicios de pronunciación a fin de que el niño perciba cuál es la sílaba que se destaca en la palabra y aprenda de esta manera a reconocer el acento de la sílaba tónica. Como actividad posterior el escolar debe aprender a separar los grupos fónicos de las palabras e identificar la posición de las sílabas -última, penúltima y antepenúltima-, todo ello como actividades previas al estudio de las palabras agudas, graves y esdrújulas.

En suma, el tratamiento ortográfico en este programa responde, en términos generales, más a la madurez de los escolares, respecto de los anteriores, los cuales se centraron en la memorización de reglas ortográficas descontextualizadas $\mathrm{y}$, por tanto, poco funcionales en los procesos de producción escrita.

1977. En esta nueva propuesta la enseñanza del léxico, de la ortografía y de la fluidez lectora se valoran mediante criterios cuantitativos. Respecto de la escritura, se establece una relación entre escritura de textos, dominio semántico del vocabulario y ortografía. Se proyecta un crecimiento en el número de vocablos por dominar en cada grado escolar, tal como se muestra a continuación:

Objetivo: El niño mostrará dominio semántico y ortográfico de (la cantidad varía según el año escolar) vocablos primitivos y de uso común.

\begin{tabular}{lllllll}
\hline Año escolar & I & II & III & IV & V & VI \\
\hline $\begin{array}{l}\text { Número de vocablos } \\
\text { por dominar }\end{array}$ & 200 & 400 & 700 & 950 & 1200 & 1500 \\
\hline
\end{tabular}

De una manera similar el uso de vocablos no repetidos en la expresión escrita presenta un patrón de crecimiento definido para cada año escolar.

Objetivo: El niño empleará con pleno dominio semántico y ortográfico, (la cantidad varía según el año escolar) vocablos no repetidos, en una expresión escrita creada.

\begin{tabular}{l|l|l|l|l|l|l}
\hline Año escolar & I & II & III & IV & V & VI \\
\hline $\begin{array}{l}\text { Número de vocablos } \\
\text { por dominar }\end{array}$ & 30 & 40 & 50 & 80 & 80 & 100 \\
\hline
\end{tabular}

Este programa no presenta las listas de los vocablos primitivos y de uso común, por tanto es difícil comprender el alcance de estos objetivos y su viabilidad en la labor cotidiana del docente. Lo que es realmente un acierto es el estudio de la ortografía a partir de la palabra de uso común y no mediante reglas.

Respecto de la producción escrita, de segundo a sexto grado se trabaja básicamente con los niveles: frase y párrafo y su uso correcto al escribir, pero se proyecta la estimulación de la expresión creativa, en el aula y durante el tiempo libre.

1979. En 1979 se publica una guía para el uso del programa vigente desde el 1977, con el fin de facilitar su puesta en práctica. En este documento se desarrollan los lineamientos básicos para la evaluación de las áreas que 
componen la asignatura de lengua materna y se hace una crítica al uso del dictado como estrategia para el dominio del código escrito y de la ortografía. Respecto de la enseñanza de la ortografía, se aboga porque el niño aprenda correctamente el vocabulario que utiliza al escribir, mediante el entrenamiento, la observación, la búsqueda y la autocorrección, todo ello bajo la guía oportuna del educador. Para guiar el logro de esta meta educativa se presenta una tabla en la cual se especifica el número de palabras por incorporar cada año, según el nivel educativo. Lamentablemente no aparecen las listas de palabras por estudiar, faltante que se justifica dado el estado de la investigación sobre la competencia lingüística de los escolares en aquella época. Sucede algo similar con la valoración del número de palabras diferentes en los escritos de los niños, directriz que supone prácticas constantes de escritura, en las cuales el nivel léxico ocupa un lugar destacado.

En suma, este manual constituye realmente el sustento teórico del programa de 1977 y, por tanto, deben valorarse los dos conjuntamente, a fin de hacer una lectura objetiva de la enseñanza de la lengua española en la educación primaria durante ese período.

1987. En 1987 se imprime una síntesis de los programas de educación primaria, en la cual se incluyen todas las asignaturas básicas y optativas, este documento se publica en vista de que se habían agotado los ejemplares de los programas vigentes. En el caso de la asignatura de Español, la síntesis consistió en la copia de los objetivos de primero a sexto grados, distribuidos en cuatro grupos: expresión oral, expresión escrita, escucha y lectura.

1991. La presente propuesta es innovadora en cuanto a la organización de los contenidos por desarrollar, la definición de un perfil general y dos específicos, uno para cada ciclo, y en la valoración del proceso de aprendizaje, no solo del producto. El programa de primer ciclo presenta en forma integrada las propuestas curriculares de Español, Estudios Sociales, Ciencias y Matemáticas, primera experiencia de esta modalidad en el país. El correspondiente a segundo ciclo mantiene la estructura tradicional, o sea, por asignaturas separadas.

En las primeras páginas de ambos programas se desarrolla brevemente el enfoque curricular, el cual responde a las preguntas: ¿para qué se aprende y se enseña?, ¿qué se aprende y qué se enseña?, ¿cómo se debe aprender y cómo se debe enseñar? y ¿cómo determinar el logro en términos de aprendizaje?

La lengua forma parte de un planteamiento curricular interactivo, en el cual el niño asume un papel protagónico como productor y receptor de textos correspondientes a temáticas diversas, pero cercanas a su realidad familiar y comunal.

La expresión oral y la escucha ocupan un lugar destacado a lo largo del programa; la conversación grupal, la exposición, la explicación, el compartir temáticas consultadas con la familia son una constante en este ciclo escolar.

La lectura oral, silenciosa y comprensiva mantienen su importancia, pero se eliminan los parámetros mínimos consignados en el programa de 1977 , por tanto, queda a criterio del docente la valoración de la fluidez y la comprensión en la lectura oral y silenciosa.

Se prescinde de la valoración del vocabulario ortográfico y de la cuantificación de la riqueza léxica, mediante la identificación del número de palabras no repetidas en un texto. La ortografía, por su parte, se sigue trabajando como parte de los criterios por considerar en la producción textual de los escolares, pero no se establecen límites por nivel.

En suma, lo valioso de este programa es la propuesta de integración de asignaturas y la convicción del trabajo equilibrado de las cuatro habilidades lingüísticas como parte de un currículum escolar.

La propuesta de segundo ciclo se divide tres áreas: expresión oral y escucha, expresión escrita y lectura, a fin de enfatizar aspectos básicos por desarrollar de forma integrada en el aula.

Las demandas en el área de la expresión escrita se centralizan en la producción de textos narrativos y descriptivos, la consulta y lectura de 
modelos textuales, la organización de esquemas previos a la escritura y la elaboración de proyectos de escritura dinamiza la producción escrita e incentiva el trabajo cooperativo.

La ortografía se valora como parte del texto, por lo que cada estudiante es responsable, junto con su maestro, de buscar las fuentes adecuadas para solucionarproblemas ortográficos en caso de haberlos. El uso del diccionario y la elaboración del propio diccionario constituyen las estrategias más recurrentes en el aprendizaje ortográfico, pero a diferencia de lo planteado para el ciclo anterior y en relación con el programa de 1977, se incorporan tímidamente algunas reglas ortográficas como objeto de estudio: uso de la "c-s-z-", el acento ortográfico y algunos signos de puntuación en cuarto grado; el uso de la "y" en palabras de uso común, uso de la "ll" en la terminación "-illo, -a" y la "b" en las terminaciones "-bilidad, bio, bunda, aba y en el prefijo bi" en quinto grado; en sexto reaparecen las reglas ortográficas necesarias, según las particularidades de los escritos de los escolares, tal como se define en el siguiente objetivo: Interpreto reglas ortográficas a partir del vocabulario común que utilizo en mis trabajos, para enriquecer mi ortografía, objetivo que induce a la elaboración de carteles con reglas ortográficas con el fin de que sean usadas en el momento oportuno.

Los temas gramaticales están prácticamente ausentes, interesan en la medida en que el texto sea comprensible. Por tanto, la autocorrección es una de las medidas asumidas, por medio del diseño de listas de cotejo que valoran estructura, contenido, puntuación, ortografía y estilo.

En suma, este programa asigna al escolar un papel protagónico en su proceso de aprendizaje y libera al educador de la valoración minuciosa de aspectos relacionados con la ortografía y la lectura.

\section{Política Educativa hacia el siglo XXI (Programas 1995, 2001 y 2005)}

1995. En este programa se conceptualiza la lengua como área instrumental, básica para la adquisición del conocimiento y la socialización; por lo que la falta de su dominio se constituye en causa de fracaso escolar.

El eje central de este programa es el siguiente: "Para efectos de la ejecución de este programa, la lectura y la expresión escrita se constituyen en núcleos integradores de actividades. La expresión oral y la escucha, sin detrimento de sus condiciones específicas, se tratarán como habilidades integradoras a ellas" (MEP, 1995:11).

La programación curricular está conformada por el desglose de contenidos, procedimientos, valores y actitudes, y criterios de evaluación para cada área objeto de estudio: expresión oral, escucha, lectura y escritura. Por tanto, desde el punto de vista de la organización interna, este programa es sustancialmente diferente del anterior (1991), el cual no especificaba contenidos, pero detallaba ampliamente las situaciones de aprendizaje; además de ilustrar, paso a paso, el trabajo con los procesos de aprendizaje.

Respecto de la ortografía, se explicita en los fundamentos del programa que no debe enseñarse de manera aislada, sino dentro de un conjunto mayor que forme al niño en la escritura. Su tratamiento será sistemático, progresivo y gradual, mediante un proceso de enseñanza y aprendizaje que, por medio de ejercitaciones diversas, conduzca al dominio de las grafías y a la formación de actitudes de cuidado y análisis de lo que se escribe. "En estas ejercitaciones debe darse lugar de privilegio a aquellas prácticas que propicien la interiorización de los patrones visuales de la correcta escritura, esto es, debe procurarse el desarrollo de la memoria visual" (MEP, 1995:18).

A manera de síntesis, el programa de 1995 muestra coherencia interna entre lo postulado como fundamento teórico y el desarrollo de las cuatro áreas del lenguaje lectura, escritura, expresión oral y escucha- a lo largo de los programas específicos de cada año. Aspectos que permiten al educador, en su función de planificador del trabajo de aula, visualizar cuál es su responsabilidad como 
guía del proceso de enriquecimiento de la lengua materna de sus alumnos.

2001. Este programa es una réplica in minuendo del programa del año 1995. En lo que atañe al cuerpo del programa queda claro que se mantienen los postulados teóricos expresados en el diseño del programa anterior, que se modifica la estructura curricular por otra organizada en columnas con una coordinación horizontal y que se presentan unos objetivos estratégicos de manera general.

2005. El Ministerio de Educación (2005) ofrece un nuevo programa, en cuya presentación señala lo siguiente: "los contenidos se han actualizado y se ha fortalecido la columna de Procedimientos y la de Valores y Actitudes, para que los docentes canalicen su accionar pedagógico en dos vertientes claramente establecidas: la rigurosidad académica ${ }^{1}$ y la formación de los principios éticos y morales, que son propios de una sociedad respetuosa de los derechos humanos, de la sexualidad humana, del entorno natural y del sistema democrático, en una cultura de paz y de consenso" (MEP, 2005:1).

La fundamentación y el enfoque de la enseñanza planteados son exactamente los mismos del programa anterior (2001) y, como consecuencia, un resumen del que se habría ofrecido en el año de 1995.

Respecto del estudio de las cuatro áreas del lenguaje, no se percibe con precisión cuál es el espacio que ocupan la lectura, la expresión oral, la escucha y la expresión escrita en este primer ciclo. Desde la perspectiva de los objetivos, pareciera que se privilegia el modelo tradicional de lengua sustentado en el enfoque gramaticalista que parte del concepto de oración como bastión fundamental de la enseñanza y el aprendizaje.

Este programa da énfasis al conocimiento del código escrito respecto del proceso de composición del texto, ya que se trabaja fundamentalmente en tres líneas: ortografía, morfología y sintaxis y léxico y en algunas reglas básicas de cohesión y coherencia, pero se obvia totalmente la adecuación textual, el aporte del lector y del texto.

\subsection{El enfoque de la enseñanza de la ortografía en Costa Rica}

El estudio de la ortografía está presente en todos los programas de educación primaria durante el período 1909-2005; el niño costarricense, por tanto, ha estudiado formalmente las variaciones en la escritura de las palabras, se ha enfrentado al uso de reglas y ha puesto en práctica numerosas estrategias conducentes a su dominio. Sin embargo, cada momento y programa de estudio ha dado diferente énfasis a este aspecto de la escritura.

En 1909 interesa resaltar la escritura de las palabras difíciles, la apropiación del vocabulario básico, tanto de lectura como de escritura, por lo que no se detallan reglas ortográficas, excepto las generales para el uso de la tilde, incorporadas a partir de tercer grado. Esta propuesta da cabida a la escritura correcta de las palabras de uso común y a la conciencia ortográfica, la cual estimula la duda e incentiva la búsqueda de la forma correcta de escribir.

La propuesta de 1926 asume la ortografía con otro sentido, las reglas ortográficas constituyen contenidos específicos desde segundo grado a quinto grado, período en el que se estudian 25 reglas, además del acento y la mayúscula. En sexto grado se repasan todas las reglas ortográficas vistas los años anteriores, ya que el alumno que concluye la educación primaria debe "escribir sin error toda palabra percibida por el oído o por la vista" (1926:67).

En 1936, el nuevo programa, continúa con la misma metodología de la enseñanza de la ortografía mediante reglas, las cuales aparecen oficialmente en segundo grado y concluyen en sexto grado con un repaso general de todas las reglas vistas.

El programa siguiente, replicado en 1962 , sin restar importancia a la ortografía, cambia de rumbo y sustituye las reglas por observaciones ortográficas, apoyadas en la representación visual de la palabra, su pronunciación y en la práctica constante de ejercicios de escritura. 
Dicho de otra manera, la ortografía se estudiará relacionada con el vocabulario usual de los escolares. No obstante, el acento y el reconocimiento de palabras agudas, graves y esdrújulas se introduce en tercer grado y se mantiene a lo largo de la escolaridad.

Ahora bien, la propuesta de 1977, es mucho más elaborada que la anterior, en el sentido de que establece criterios cuantitativos para valorar el dominio semántico y ortográfico de los vocablos de uso común en los escritos de los niños. Es destacable la claridad en el planteamiento teórico-metodológico, o sea, escritura correcta de las palabras de uso común, a pensar de que no se incluye un listado de vocablos comunes, o bien la guía para identificar el vocabulario cacográfico en los escritos de los escolares. Al igual que en las propuestas anteriores, el acento ortográfico se introduce en tercer grado.

La siguiente entrega, el programa integrado para I ciclo, 1991, continúa con la valoración de la ortografía a partir de las dificultades encontradas por los alumnos al escribir sus trabajos, por tanto, no se recurre a las reglas y se valora al diccionario como medio de consulta y se promueve la elaboración del propio, estrategias recurrentes en el aprendizaje ortográfico, con excepción del uso de la "c-s-z" y el acento ortográfico en tercer grado. En segundo ciclo se continúa con la misma metodología, pero se adicionan cinco reglas ortográficas.

El primer programa enmarcado en la Política Educativa hacia el Siglo XXI, 1995, aborda la ortografía como se venía haciendo en el programa anterior: estudio de las dificultades ortográficas a partir del texto escrito por los escolares. En tercer grado se estudia explícitamente la regla del uso de la m antes de b y p; en cuarto grado se añade el estudio del acento ortográfico y el uso de s, c y z; en quinto el uso de la b y la v; en sexto el uso correcto de ge, gi, güe, güi y de la j y de la g. Como puede notarse puede decirse que las reglas ortográficas prácticamente no se consideraron temáticas de estudio en la educación primaria.
Regresan las reglas ortográficas, 2001 y 2005, programas hermanos de la Política Educativa hacia el Siglo XXI, saturados de contenidos ortográficos, desglosados en reglas colocadas indiscriminadamente año tras año, sin razón aparente. Cabría preguntarse por qué se seleccionaron esas reglas y cuál fue el criterio científico para hacerlo. Pareciera, a juzgar por este programa, que un niño al concluir sexto grado debe conocer todas las reglas ortográficas que aparecen en los manuales, metodología que no ha deparado la formación ortográfica adecuada; también cabía preguntarse el porqué de su pertinencia y permanencia en los programas.

Es obvio que es necesario un cambio de paradigma en la enseñanza de la ortografía; se cuenta hoy con suficientes datos, aportados por estudios de investigación, para definir, en caso de estudiar reglas ortográficas, cuáles son más rentables, o sea, cuáles se aplican al mayor número de palabras, en qué momento es adecuado introducirlas y cuál metodología asegura mayor éxito en esta empresa.

En síntesis, la ortografía en la escuela primaria se ha abordado básicamente mediante el conocimiento y aplicación de las reglas ortográficas emitidas por la Real Academia Española, sin distinguir su rentabilidad, utilidad y su relación con la etapa de desarrollo de la escritura en los niños y sus capacidades cognitivas, asociadas con el desarrollo evolutivo del escolar. Unido a lo anterior, han aparecido en diferentes momentos otras estrategias subordinadas a las reglas: recomendaciones u observaciones ortográficas y el dominio de un vocabulario básico ortográfico.

En vista de lo anterior, es necesario un replanteamiento de la enseñanza de la ortografía a la luz de los datos aportados por la investigación lingüístico-educativa, los avances en el abordaje de la enseñanza de la lengua como área instrumental para la comunicación, el aprendizaje y la socialización, la incorporación de la psicopedagogía en los nuevos planteamientos curriculares- estilos de aprendizaje- y la valoración del niño como persona en proceso de desarrollo. 


\section{La competencia ortográfica de los escolares}

La competencia ortográfica de los escolares costarricenses ha sido objeto de estudio desde diferentes perspectivas por docentes e investigadores. En este sentido se han planteado estrategias metodológicas con un fuerte componente lúdico, estrategias basadas en el estudio de reglas ortográficas y otras a partir de la producción textual del alumno. No obstante, pese a la preocupación manifiesta de forma constante y a lo largo de los años los estudiantes continúan presentando problemas ortográficos al producir textos escolares y extraescolares.

La competencia reducida al escribir con ortografía genera preguntas y respuestas que no necesariamente atienden a las motivaciones reales de los resultados deficientes en la práctica ortográfica en los escolares, por ejemplo en los medios de comunicación colectiva se señala con cierta frecuencia esta situación y sostienen tesis a veces equivocadas o bien que responden a creencias populares, como por ejemplo:

Ortografía se come a estudiantes por escasa lectura y redacción. (La Nación, 22 de julio de 2012). Se resalta que "los especialistas dicen que en las aulas se dejó de hacer dictados y revisar redacciones" (...) "Asociación de Profesores de Español pide cambio en programas". Esas ideas en alguna medida se legitimizan y depositan la responsabilidad del aprendizaje ortográfico en el docente, quien no hace lo suficiente para que el alumno escrita con ortografía y, por tanto, se añoran prácticas pedagógicas provenientes de enfoques curriculares superados, pero que permanecen en la memoria de los usuarios de la lengua, como lo es la copia. Lo mismo sucede con un eventual cambio de programas, sin necesariamente enfatizar en la puesta en práctica de estrategias pedagógicas que respondan al desarrollo cognitivo del escolar, sus competencias lingüísticas, la motivación para el aprendizaje, la mediación pedagógica y la definición de prioridades educativas por ciclo y año escolar, además de la incomprensión de que en las etapas del aprendizaje ortográfico: "conciencia ortográfica" y "el aprendizaje de la ortografía propiamente dicho", median otros aspectos ligados al aprendizaje de la escritura y de la producción escrita

Reportajes sobre la temática comentada en el párrafo anterior, generan reflexión y la necesidad de seguir retomando el tema, en vista de su trascendencia socioeducativa. En este sentido el periodista Julio Rodríguez en un artículo de opinión publicado el 13 de agosto de 2012, retoma la información relativa a las desventuras de la ortografía, la lectura y la redacción, del reportaje del 22 de julio y afirma que cree que no haya otra noticia que supere esta por sus consecuencias en la formación y desarrollo del pueblo. Además, lamenta que este tipo de noticas pasen sin generar espacios de reflexión conducentes al cambio y critica, sin dejar pasar la oportunidad, "la enseñanza mediocre en la escuela y en el colegio".

Por otra parte, en el seno del Ministerio de Educación Pública se reconoce la urgencia de plantear estrategias de cambio frente a un programa que privilegia el uso constante de reglas ortográficas, en opinión del asesor de Español, Ángel Alvarado (La Nación, 22 de julio, 2012).

Desde el punto de vista de la lingüística educativa y la didáctica de la lengua se ha estudiado este aspecto del código escrito y se han identificado los tipos de errores más comunes, analizado los programas de estudio y revisado los libros de texto, a fin de plantear soluciones a partir de la competencia del escolar y de los resultados de las investigaciones de disciplinas afines.

En este sentido, Murillo Rojas (2004) identifica los errores más comunes a partir del análisis de producciones escritas de escolares costarricenses con una muestra a nivel nacional; Sánchez Avendaño (2008) analiza los libros para la enseñanza de la ortografía en Costa Rica, el problema de las reglas ortográficas, el diagnóstico 
de las cacografías en la población estudiantil del país, las causas de las disortografías y algunos aspectos en torno a la enseñanza de este componente del registro escrito.

Chavarría Aguilar (1988), citado por Sánchez Avendaño (2008) señala que los hablantes "comenten faltas de ortografía en los casos en los que existen alternantes gráficos para la representación de una misma unidad fonológica : /b/ representado con $\mathrm{b} \sim \mathrm{v}$ : barco, vaso; /s/ representado con $\mathrm{s} \sim \mathrm{c} \sim \mathrm{z}$ (especialmente en el caso de Hispanoamérica): saco, cielo, zapato; / $\mathrm{x} /$ representado con $\mathrm{g} \sim \mathrm{j}$ : gitano, jinete; $h$ que no representa nada (usualmente empleada por tradición etimológica): hielo, anhelar; /j/ representado con $11 \sim$ y: llave, yegua; $/ \mathrm{n} /$ representado con $\mathrm{m} \sim \mathrm{n}$ (antes de otra consonante): ambos, antes; $/ \mathrm{k} /$ representado con $\mathrm{c} \sim$ qu: cuero, queso; $/ \mathrm{r} /$ representado con $\mathrm{r} \sim \mathrm{rr}$ : ratón, carro, alrededor, enredo; /ks/ representado con $\mathrm{x} \sim$ cc: conexión, acceso.” (p. 103).

Rodino y Ross, 1985, encuentran en producciones escritas de estudiantes universitarios confusiones de letras y falta de tildes.

Murillo Rojas (2004) señala que los dos caballos de batalla en la escritura con ortografía son, por un lado, la marcación gráfica del acento, según las reglas establecidas $\mathrm{y}$, por el otro, la escritura de los fonemas /b/,/s/, /y/, /r/ y la hache. Es oportuno señalar que en esta investigación se identifican las 100 palabras gráficas con mayor incidencia de errores ortográficos y el tipo de dificultad que poseen. Como parte de esas 100 palabras aparecen 11 sustantivos, de los cuales 10 se tildan -país, papá, mamá, tío, pájaro, día, árbol, río, contaminación, fútbol-; 12 adverbios -ahora, ya, dónde, aquí, sí, ahí, entonces, bien, después, siempre, también, así; seis adjetivos -feliz, joven, único, último, mi, mío- dos preposiciones -a, hasta-, cinco pronombres personales: yo, él, interrogativos: qué, quién, cuál-; dos conjunciones -porque, y-; y 59 verbos.

En suma, es evidente que la ortografía constituye una dificultad en la escritura de los estudiantes de primaria y secundaria costarricenses, pero también es cierto que la investigación realizada a la fecha permite tomar decisiones para abordar su estudio de una forma integral y productiva en pro de una adecuada enseñanza de la lengua española.

\section{Estrategias didácticas para la enseñanza de la ortografía española}

La ortografía española en Costa Rica y en muchos otros países se ha enseñado básicamente mediante el estudio y memorización de reglas ortográficas, sistema de enseñanza que, tal como muestran las investigaciones, no ha dado los resultados esperados en la educación básica. Repetir este sistema de enseñanza en respuesta al poder de la tradición reflejada en los programas de estudio, no hará que este método mejore y sea productivo. Por tanto, lo que cabe es preguntarse qué otras rutas de aprendizaje y de enseñanza serían más acertadas para que el alumno escriba con ortografía. En este sentido, es útil cuestionarse acerca de cuáles son los objetivos de la enseñanza de la ortografía en los diferentes ciclos escolares y las proyecciones pedagógicas en relación con la competencia lingüístico-comunicativa del escolar y su desarrollo cognitivo y la motivación para el aprendizaje escolar.

Bajo la perspectiva señalada el objetivo fundamental de la enseñanza de la ortografía es lograr que los "alumnos escriban correctamente todas las palabras que utilicen, y tengan vehículos de incorporación para las palabras que irán conociendo en el futuro" (Parera Parramon et al, 1996:30). De acuerdo con ese objetivo el alumno debe escribir el vocabulario personal de escritura con corrección ortográfica y conocer estrategias para escribir correctamente las nuevas palabras que escribirá en el futuro. Es fundamental entonces identificar el vocabulario que usa el alumno al escribir y la enseñanza de estrategias para enfrentar la escritura de nuevas palabras.

Indudablemente el aprendizaje ortográfico es parte de la didáctica de la escritura, la cual concebida como producción textual tiene como 
objeto de estudio el texto y los elementos que lo conforman, entre ellos la ortografía.

Circunscribiéndonos en las estrategias específicas para el aprendizaje ortográfico habría que trabajar en cinco direcciones:

1. Desarrollo de la "conciencia ortográfica", o sea, la manifestación de una "actitud positiva hacia el aprendizaje y uso de la Ortografía y un afán de perfeccionamiento en ella, solventando las dudas y rechazando los errores" (Mesanza López, 1987:61).

2. Desarrollo de competencias de lectura y escritura comprensivas.

3. Aprendizaje de la estrategia ortográfica visual. (Garrabó, 2010)

4. Vocabulario personal y palabras de mayor frecuencia al escribir. El alumno debe escribir con corrección las palabras que utiliza en sus producciones escritas.

5. Uso de reglas ortográficas rentables. El acento ortográfico.

La primera, conciencia ortográfica, corresponde a un objetivo actitudinal prioritario en el aprendizaje de la ortografía, el cual va unida a la apertura de espacios para que el alumno pregunte $\mathrm{y}$, de esta manera, desarrolle la conciencia de las posibilidades de error que existen al escribir y, poco a poco, vaya apropiándose de las fuentes y estrategias pertinentes para obtener las informaciones requeridas. Dicho de otra manera, la pregunta es, en este caso, más importante que la respuesta. Este aspecto requiere del conocimiento profundo del docente acerca de la categorización de las dificultades de la escritura del español, tal como lo presenta Grompone de Carbonell (2004) al hacer una clasificación estructural de los errores ortográficos, con el propósito de ubicar el nivel del alumno respecto del dominio de este aspecto de la escritura.

El segundo, desarrollo de competencias de lectura y escritura comprensivas, al ser la ortografía un aspecto de la escritura no puede tratarse como elemento independiente, pues se requiere un dominio medio de estas competencias para tornar significativo el estudio de las palabras y su correcta escritura. No obstante, es oportuno tener en cuenta que la ortografía se circunscribe a la mera representación gráfica de las palabras y que su acatamiento es obligatorio.

El tercer aspecto, aprendizaje de la estrategia ortográfica visual, para Garrabó (2010) las personas con buena ortografía ven en su mente la imagen de las palabras que quieren escribir, esta afirmación se sustenta en los principios teórico-prácticos de la programación neurolingüística y en la experiencia acumulada con docentes y estudiantes en la enseñanza de estrategias para el aprendizaje de la ortografía. En este sentido los alumnos con mala ortografía no dominan la estrategia mental adecuada o sea no aplican la memoria visual a la ortografía.

El siguiente punto, vocabulario personal y palabras de mayor frecuencia al escribir, señala que el dominio de la ortografía responde, en gran medida, al dominio de un corpus léxico individual, que utiliza cada persona al escribir, unido al conocimiento ortográfico de las palabras de mayor frecuencia al escribir en español, lo cual permite al escribiente reducir significativamente los errores ortográficos y tornar más significativo el estudio de la ortografía. De ahí la utilidad de los vocabularios cacográficos y el desarrollo de estrategias visuales para la incorporación de esas palabras.

Finalmente, las reglas ortográficas rentables, cumplen su función en una etapa media y avanzada en el aprendizaje de la ortografía del español. Las reglas ortográficas rentables se extraen del análisis de los errores más frecuentes que cometen los escolares en el proceso de apropiación de la escritura. Además para su identificación se debe considerar la transparencia en su comprensión, la aplicación general y sin posibilidad de excepciones, pues de lo contrario no tendrían utilidad.

Las estrategias señaladas no corresponden a un grado o a un ciclo educativo específico, sino que permanecen como estrategias de trabajo continuo durante toda la educación básica. 


\section{La enseñanza de la ortografía en la escuela costarricense}

A partir de la lectura de Garrabó y Puigarnau (1996), Salgado (1997), Camps et al (2004), Carbonell de Grompone (2004), Barberá (1988), Rodríguez, (1996), Murillo (2004) y Sánchez (2008), Garrabó (2010) se señalan como objetivos fundamentales de la enseñanza de la ortografía en la educación primaria:

1. Desarrollar en los alumnos una conciencia ortográfica y el conocimiento de las múltiples posibilidades de error al escribir en español.

2. Desarrollar la estrategia ortográfica visual para la incorporación global cada palabra.

3. Escribir correctamente las palabras que forman parte del vocabulario básico ortográfico.

4. Incorporar la autocorrección del trabajo escrito como instrumento para subsanar todas las posibilidades de error.

El aprendizaje de la ortografía sólo tiene sentido si se enmarca en un aprendizaje de la lengua escrita entendida como capacidad para la expresión y comunicación por escrito. El niño comprenderá la necesidad de la ortografía únicamente si siente la necesidad de escribir" (Camps, 2004:42).

Es necesario clarificar el lugar que ocupa la ortografía en el proceso de escritura, pues la producción de un texto implica la organización de las ideas que se quieren explicar, la intención del texto, la adecuación al lector, la forma sintáctica de los enunciados, la selección del vocabulario, la forma gráfica de las palabras, todos aspectos que debe controlar el escritor y a los cuales se debe prestar atención y, en consecuencia, programar su enseñanza.

A continuación se presenta la propuesta de la enseñanza de la ortografía para la escuela primaria organizadas trimestralmente y el desglose del vocabulario básico cacográfico por incorporar durante cada período educativo.

\section{Propuesta programación del aprendizaje ortográfico en la escuela primaria costarricense}

\section{Programación del aprendizaje ortográfico}

Primer grado: I, II y III trimestre

1. Consolidar el aprendizaje de la lectoescritura inicial.

2. Iniciar en el uso de las mayúsculas al escribir nombres de personas y en la primera letra de un escrito y después de punto.

3. Escribir correctamente el nombre propio y los apellidos.

4. Escribir los nombres de los números cardinales del 0 al 10 .

5. Estudio de la secuencia de las sílabas: ca, que, qui, co, cu.

6. Estudio de la secuencia de las sílabas: ga, gue, gui, go, gu.

Segundo grado: I trimestre

1. Estudio de la secuencia de las sílabas: ga, gue, gui, go, gu.

2. Estudio de la secuencia de las sílabas: ca, que, qui, co, cu.

3. Estudio de la secuencia de las sílabas: za, ce, ci, zo, zu.

4. Estudio de las sílabas güe y güi.

5. Escribir los nombres de los números cardinales de 0 al 20.

6. Escribir los nombres de los días de la semana.

Nota: Los puntos del 1 al 6 se trabajarán hasta que el niño los domine. 
Segundo grado: II trimestre

\section{Vocabulario básico ortográfico \\ 1. Palabras del vocabulario básico ortográfico.}

$\begin{array}{lllll}\text { amigo } & \text { es } & \text { hago } & \text { limpio } & \text { somos } \\ \text { árbol } & \text { está } & \text { hambre } & \text { mamá } & \text { soy } \\ \text { así } & \text { estaban } & \text { hay } & \text { más } & \text { también } \\ \text { bien } & \text { estar } & \text { herida } & \text { miércoles } & \text { usted } \\ \text { bonito } & \text { estoy } & \text { hermano } & \text { nuevo } & \text { va } \\ \text { bosque } & \text { haber } & \text { hice } & \text { pájaro } & \text { vamos } \\ \text { bueno } & \text { había } & \text { inteligente } & \text { papá } & \text { viejo } \\ \text { después } & \text { habían } & \text { ir } & \text { río } & \text { viernes } \\ \text { él } & \text { hacer } & \text { jardín } & \text { sábado } & \text { voy } \\ \text { ella } & \text { hacía } & \text { jueves } & \text { ser } & \text { ya } \\ \text { entonces } & \text { hada } & \text { juguetón } & \text { siempre } & \text { yo }\end{array}$

2. Mayúscula al comenzar un escrito y después de punto.

Segundo grado: III trimestre

1. Palabras del vocabulario básico ortográfico.

$\begin{array}{llll}\text { ácido } & \text { feroz } & \text { hacían } & \text { mayor } \\ \text { águila } & \text { fue } & \text { hago } & \text { mayoría } \\ \text { ahí } & \text { fueron } & \text { hamaca } & \text { público } \\ \text { ahora } & \text { fui } & \text { hambre } & \text { rápido } \\ \text { allí } & \text { fuimos } & \text { hasta } & \text { ser } \\ \text { ángel } & \text { fútbol } & \text { hemos } & \text { sería } \\ \text { aquí } & \text { futbolista } & \text { hicieron } & \text { siguiente } \\ \text { barco } & \text { haber } & \text { hizo } & \text { vacilón } \\ \text { cabeza } & \text { hace } & \text { hombre } & \text { van } \\ \text { cerdo } & \text { hacemos } & \text { inmenso } & \text { viejo } \\ \text { común } & \text { hacen } & \text { ir } & \text { y } \\ \text { conseguir } & \text { hacer } & \text { joven } & \\ \text { era } & \text { hacíamos } & \text { matemáticas } & \\ \text { esto } & & \text { música } & \end{array}$

2. Mayúscula al comenzar un escrito, después de punto, nombres de lugares.

Tercer grado: I trimestre

1. Palabras del vocabulario básico ortográfico.

$\begin{array}{lllll}\text { abajo } & \text { bebé } & \text { hacer } & \text { lástima } & \text { todavía } \\ \text { abeja } & \text { bicicleta } & \text { haciendo } & \text { león } & \text { van } \\ \text { además } & \text { bien } & \text { hecho } & \text { lobo } & \text { vaya } \\ \text { ahí } & \text { café } & \text { hormiga } & \text { mágico } & \text { vayamos } \\ \text { ahora } & \text { cansar } & \text { hoy } & \text { manzana } & \text { vayan } \\ \text { allá } & \text { casi } & \text { iba } & \text { mayoría } & \text { venganza } \\ \text { allí } & \text { demasiado } & \text { íbamos } & \text { monstruo } & \text { venir } \\ \text { anteayer } & \text { después } & \text { iban } & \text { música } & \text { ver } \\ \text { aquí } & \text { entonces } & \text { iglesia } & \text { pedazo } & \text { volcán } \\ \text { arriba } & \text { era } & \text { inglés } & \text { plástico } & \text { volver } \\ \text { así } & \text { esté } & \text { insecto } & \text { policía } & \text { ya } \\ \text { aunque } & \text { gente } & \text { interés } & \text { príncipe } & \\ \text { bastante } & \text { guerra } & \text { lápices } & \text { siempre } & \\ & \text { habían } & \text { lápiz } & \text { también } & \end{array}$

2. Mayúscula en nombres propios, al comenzar un escrito y después de punto.

3. La formación del plural en español.

Tercer grado: II trimestre

1. Palabras del vocabulario básico ortográfico.

$\begin{array}{llll}\text { a veces } & \text { dieron } & \text { naturaleza } & \text { quizá } \\ \text { abuelo } & \text { difícil } & \text { número } & \text { tal vez } \\ \text { adiós } & \text { dio } & \text { oí } & \text { tío } \\ \text { carrera } & \text { dónde } & \text { oían } & \text { último } \\ \text { carro } & \text { doy } & \text { oír } & \text { único } \\ \text { cierto } & \text { entrar } & \text { oye } & \text { útil } \\ \text { comencé } & \text { entré } & \text { oyó } & \text { vez } \\ \text { comenzaron } & \text { entró } & \text { por favor } & \text { volver } \\ \text { comenzó } & \text { fácil } & \text { por qué } & \text { volví } \\ \text { corazón } & \text { gracias } & \text { porque } & \text { volvieron } \\ \text { cuál } & \text { hermoso } & \text { precioso } & \text { volvió } \\ \text { cuándo } & \text { inútil } & \text { qué } & \\ \text { cuánto } & \text { nariz } & \text { quién } & \end{array}$


2. Palabras derivadas de la misma familia escritas con las letras b y v. Ej. : caballo -caballería, cabalgata, caballeriza, caballada, etc.-, avión -avioneta, aviación, aviador, etc.-

Tercer grado: III trimestre

1. Palabras del vocabulario básico ortográfico.

$\begin{array}{lllll}\text { abajo } & \text { bastante } & \text { entonces } & \text { hoy } & \text { sí } \\ \text { además } & \text { bien } & \text { está } & \text { iba } & \text { siempre } \\ \text { ahí } & \text { casi } & \text { estaba } & \text { íbamos } & \text { soy } \\ \text { ahora } & \text { cierto } & \text { fábrica } & \text { limón } & \text { también } \\ \text { allá } & \text { cuál } & \text { fantasía } & \text { líquido } & \text { todavía } \\ \text { allí } & \text { cuándo } & \text { fue } & \text { lobo } & \text { va } \\ \text { anteayer } & \text { cuánto } & \text { fuéramos } & \text { luz } & \text { vamos } \\ \text { aquí } & \text { demasiado } & \text { fueron } & \text { maíz } & \text { voy } \\ \text { arriba } & \text { después } & \text { fui } & \text { por qué } & \text { ya } \\ \text { así } & \text { dónde } & \text { había } & \text { qué } & \\ \text { aunque } & \text { dónde } & \text { hacía } & \text { quién } & \\ \text { ayer } & \text { él } & \text { hasta } & \text { quizá } & \end{array}$

2. La división silábica y el reconocimiento de la sílaba tónica en la palabra.

Cuarto grado: I trimestre

1. Palabras del vocabulario básico ortográfico.

\begin{tabular}{|c|c|c|c|c|}
\hline andaba & compraba & decidí & 1legué & quise \\
\hline andar & compré & decidía & 1levaba & sabía \\
\hline anduve & convertí & decidir & 1levar & sentí \\
\hline aparecer & convertía & echaba & 1levé & $\begin{array}{l}\text { sen- } \\
\text { tía }\end{array}$ \\
\hline aparecí & convertir & echar & nacer & veía \\
\hline aparecía & correr & eché & nací & ver \\
\hline ayudaba & corrí & hablaba & nacía & vi \\
\hline ayudar & corría & hablar & peleaba & viví \\
\hline ayudé & deber & hablé & pelear & vivía \\
\hline caí & debí & 1legaba & peleé & vivir \\
\hline caía & debía & 1legar & quería & \\
\hline
\end{tabular}

2. Conjugación completa del verbo ir

Cuarto grado: II trimestre

1. Palabras del vocabulario básico ortográfico.

$\begin{array}{llll}\text { abundante } & \text { azul } & \text { cemento } & \text { disciplina } \\ \text { acercar } & \text { ballena } & \text { compañero } & \text { divertir } \\ \text { acuático } & \text { básico } & \text { compresión } & \text { entraba } \\ \text { aéreo } & \text { bastante } & \text { confianza } & \text { entré experiencia } \\ \text { agarrar } & \text { basura } & \text { conocer } & \text { hacia } \\ \text { alegría } & \text { belleza } & \text { convertir } & \text { hola } \\ \text { alemán } & \text { bello } & \text { correr } & \text { hormiguita } \\ \text { ansioso } & \text { biológico } & \text { creer } & \text { jardín } \\ \text { atmósfera } & \text { campesino } & \text { cueva } & \text { levantar } \\ \text { atmosférico } & \text { carácter } & \text { decidir } & \text { observar } \\ \text { automóvil } & \text { cárcel } & \text { destrucción } & \text { piscina } \\ \text { avión } & \text { cementerio } & \text { detrás } & \text { tampoco } \\ & & & \text { únicamente }\end{array}$

2. Conjugación completa del verbo estar.

Cuarto grado: III trimestre

1. Palabras del vocabulario básico ortográfico.

$\begin{array}{lllll}\text { acto cívico } & \text { cámara } & \text { crecer } & \text { necesidad } & \text { redacción } \\ \text { águila } & \text { cáncer } & \text { esforzar } & \text { necesitar } & \text { reír } \\ \text { balcón } & \text { canción } & \text { existir } & \text { ojalá } & \text { riqueza } \\ \text { bomba } & \text { caníbal } & \text { helicóptero } & \text { panza } & \text { satélite } \\ \text { borracho } & \text { capaz } & \text { humo } & \text { peces } & \text { según } \\ \text { botánico } & \text { carnívoro } & \text { llorar } & \text { pez } & \text { serpiente } \\ \text { bravo } & \text { celeste } & \text { lombrices } & \text { príncipe } & \text { tecnología } \\ \text { brazo } & \text { centro } & \text { lombriz } & \text { profesión } & \text { tortuguita } \\ \text { cabeza } & \text { cercano } & \text { montón } & \text { pulpería } & \\ \text { café } & \text { científico } & \text { navidad } & \text { razón } & \end{array}$


2. Conjugación completa del verbo haber.

Quinto grado: I trimestre

1. Palabras del vocabulario básico ortográfico.

$\begin{array}{llll} & & & \\ \text { alguien } & \text { clásico } & \text { hospital } & \text { vicio } \\ \text { algún } & \text { clínica } & \text { ningún } & \text { vida } \\ \text { alrededor } & \text { cocina } & \text { selva } & \text { volcán } \\ \text { aproximadamente } & \text { colorín } & \text { teléfono } & \text { zacate } \\ \text { aún } & \text { cómodo } & \text { televisión } & \text { zanahoria } \\ \text { cáscara } & \text { compañía } & \text { tiempo } & \text { zombi } \\ \text { Centro América } & \text { común } & \text { tristeza } & \text { zompopa } \\ \text { cerca } & \text { conocimiento } & \text { universidad } & \text { zopilote } \\ \text { circo } & \text { consciente } & \text { vacaciones } & \\ \text { cisne } & \text { costarricense } & \text { vago } & \\ \text { ciudadanía } & \text { débil } & \text { vehículo } & \\ \text { ciudadano } & \text { delicioso } & \text { verdad } & \\ \text { cívico } & \text { demás } & \text { vestido } & \end{array}$

2. Conjugación completa del verbo hacer.

Quinto grado: II trimestre

1. Palabras del vocabulario básico ortográfico.

$\begin{array}{llll}\text { aceptar } & \text { específicamente } & \text { pétalo } & \text { vecindad } \\ \text { agradecer } & \text { necesario } & \text { petróleo } & \text { vecino } \\ \text { cambiar } & \text { obediente } & \text { plástico } & \text { venado } \\ \text { cazar } & \text { omnívoro } & \text { playa } & \text { vender } \\ \text { descendiente } & \text { paciente } & \text { plaza } & \text { veterinario } \\ \text { desobediente } & \text { pálido } & \text { profesional } & \text { violencia } \\ \text { diabólico } & \text { pérdida } & \text { próximo } & \text { visitar } \\ \text { diverso } & \text { perdón } & \text { proyecto } & \text { volar } \\ \text { doméstico } & \text { pereza } & \text { ratón } & \text { zapato } \\ \text { económico } & \text { perezoso } & \text { sucesivamente } & \text { zona } \\ \text { egoísta } & \text { periódico } & \text { tiburón } & \\ \text { escoger } & \text { perseguir } & \text { título } & \end{array}$

2. Conjugación completa del verbo saber.

Quinto grado: III trimestre

\section{Palabras del vocabulario básico} ortográfico.

$\begin{array}{llll}\text { abrazar } & \text { excelente } & \text { policía } & \text { trabajo } \\ \text { almorzar } & \text { exceso } & \text { poza } & \text { transcurso } \\ \text { amanecer } & \text { extenso } & \text { preocupación } & \text { travieso } \\ \text { celebrar } & \text { extranjero } & \text { prójimo } & \text { vacilón } \\ \text { cerrar } & \text { extraterrestre } & \text { propósito } & \text { variedad } \\ \text { construir } & \text { hallar } & \text { quetzal } & \text { veloz } \\ \text { desaparecer } & \text { invitar } & \text { químico } & \text { venganza } \\ \text { especial } & \text { lavar } & \text { receta } & \text { vestir } \\ \text { especie } & \text { paraíso } & \text { recompensa } & \text { vuelto } \\ \text { espléndido } & \text { película } & \text { restaurante } & \\ \text { estricto } & \text { pellizco } & \text { risa } & \\ \text { evangélico } & \text { perro } & \text { secreto } & \end{array}$

2. Conjugación completa del verbo ser.

Sexto grado: I trimestre

1. Palabras del vocabulario básico ortográfico.

$\begin{array}{llll}\text { abeja } & \text { aventura } & \text { encerrar } & \text { hipótesis } \\ \text { abogado } & \text { balazo } & \text { extrañar } & \text { historia } \\ \text { adolescencia } & \text { chapuzón } & \text { felices } & \text { hogar } \\ \text { adolescente } & \text { corazón } & \text { feroces } & \text { hongo } \\ \text { aeromoza } & \text { costarricense } & \text { físico } & \text { honrado } \\ \text { apoyar } & \text { decisión } & \text { grave } & \text { hospital } \\ \text { apreciar } & \text { deforestación } & \text { hábitat } & \text { hueco } \\ \text { aprovechar } & \text { derribar } & \text { hambriento } & \text { hueso } \\ \text { arreglar } & \text { desierto } & \text { herbívoro } & \text { huevo } \\ \text { atención } & \text { devolver } & \text { hermoso } & \text { huir } \\ \text { aula } & \text { diciembre } & \text { hidroeléctrico } & \text { llenar } \\ \text { autobús } & \text { embarazar } & \text { hijo } & \text { observar } \\ & & & \end{array}$


2. Conjugación completa del verbo caer.

Sexto grado: II trimestre

1. Palabras del vocabulario básico ortográfico.

$\begin{array}{llll}\text { advertencia } & \text { aeropuerto } & \text { alcohólico } & \text { alcoholismo } \\ \text { almohada } & \text { encía } & \text { extranjero } & \text { imposible } \\ \text { almuerzo } & \text { energía } & \text { geógrafo } & \text { incendio } \\ \text { arco iris } & \text { enseñanza } & \text { guerrero } & \text { increíble } \\ \text { dimensión } & \text { época } & \text { guía } & \text { inglés } \\ \text { dirección } & \text { erupción } & \text { habitación } & \text { inútil } \\ \text { disfraz } & \text { espíritu } & \text { horrible } & \text { kilómetro } \\ \text { diversión } & \text { examen } & \text { huérfano } & \text { ñampí } \\ \text { dragón } & \text { exámenes } & \text { humano } & \text { obstáculo } \\ \text { drogadicción } & \text { excepción } & \text { humilde } & \\ \text { ejército } & \text { éxito } & \text { idéntico } & \\ \text { electricidad } & \text { extinción } & \text { imagen } & \end{array}$

2. Las terminaciones -aba, -abas, -ábamos, -aban de los verbos en pasado (pretérito imperfecto de indicativo de los verbos de la primera conjugación).

3. Los verbos deber, beber, haber.

Sexto grado: III trimestre

1. Palabras del vocabulario básico ortográfico.

$\begin{array}{llll}\text { ánimo } & \text { humano } & \text { máquina } & \text { negocio } \\ \text { astronauta } & \text { inútil } & \text { maravilloso } & \text { ocasión } \\ \text { felicidad } & \text { investigación } & \text { marihuana } & \text { océano } \\ \text { fósforo } & \text { izquierdo } & \text { marítimo } & \text { orquídea } \\ \text { grave } & \text { maldición } & \text { máximo } & \text { oxígeno } \\ \text { hacha } & \text { malhechor } & \text { medicinal } & \text { pabellón } \\ \text { hendija } & \text { malvado } & \text { método } & \\ \text { herida } & \text { mamífero } & \text { murciélago } & \end{array}$

2. Acentuación de la sílaba tónica en palabras agudas, graves y esdrújulas.

3. Los verbos deber, beber, saber, haber.
4. El uso de la "rr" en palabras que tienen sonido vibrante múltiple en posición intervocálica.

5. Secuencias mp y mb.

6. Homófonos, tilde en exclamaciones e interrogaciones y diacríticos.

6.1. La tilde en exclamaciones e interrogaciones

cual / cuál (pron. interrog.)

porque / por qué (pron. interrog.)

que / qué (pron. interrog.)

quien / quién (pron. interrog.)

donde / dónde (pron. interrog.)

6.2. Los acentos diacríticos

Algunas palabras pueden escribirse con o sin tilde, depende del significado en el contexto del enunciado.

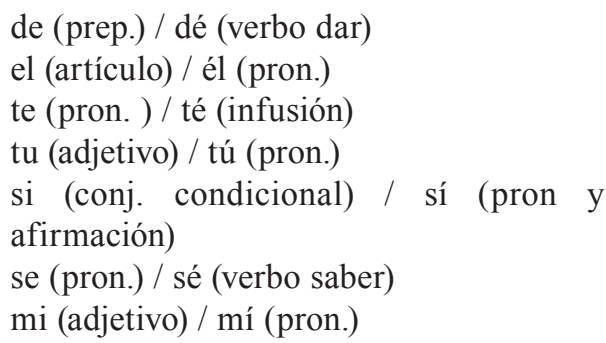

6.3. Homófonos

El trabajo con homófonos ubica a la ortografía en el nivel de la oración o del enunciado, pues solamente a partir del texto es posible elegir la ortografía adecuada de la palabra.
esta / está
este / esté
votar / botar

Recuérdese que las reglas ortográficas rentables y entre estas las de acentuación se seguirán trabajando durante la educación secundaria, pues la ortografía no se desarrolla de forma lineal sino que es preciso retomar, año tras año, los contenidos y objetivos vistos.

A continuación se presenta un ejemplo de secuencia didáctica de ortografía, con el fin de mostrar como introducir el tema de 
la conciencia ortográfica y en particular las diferentes formas en que podría escribirse una palabra y la necesidad de elegir correcta, según la normativa académica.

\section{Un ejemplo}

Secuencia didáctica: Los nombres de mis familiares y amigos

Resumen: Esta secuencia didáctica está dirigida a niños de primer grado escolar de la educación general básica costarricense y se orienta al reconocimiento de las características de la escritura de los nombres propios, para lo cual se tomarán como ejemplos los nombres de los familiares y amigos de los escolares.

La intención es que el escolar tome conciencia de las posibilidades gráficas que tienen algunos fonemas de la lengua española, lo que obliga al escritor a elegir entre una u otra forma gráfica, según la palabra de que se trate. Por ejemplo, que el alumno sepa que el fonema /b/ puede escribirse como uve o como be, según la palabra, aunque auditivamente sean idénticos.

Tarea final: Identificar las regularidades e irregularidades ortográficas en los nombres propios objeto de estudio.

\section{Objetivos:}

1. Agrupar los nombres que forman parte del corpus en estudio, según algunas de sus características: longitud, uso de tilde, uso de consonantes idénticas, uso de letras diferentes para representar el mismo sonido.

2. Activar la conciencia de las posibilidades de escritura de algunos fonemas del español: /b/, /s/, /y/

\section{Sesiones de trabajo: seis}

Tema: Conciencia ortográfica. Actividades

1. Juguemos con nuestros nombres (1 sesión)

Se solicita a los alumnos que pasen a la pizarra y escriban su nombre; pueden pasar de cinco en cinco niños, según el tamaño de la pizarra y la cantidad de tiza o marcadores con que se cuente.

Seguidamente se conversa sobre las características de los nombres de los niños: ¿cuáles inician con el mismo sonido?, ¿cuáles terminan igual?, ¿cuáles tienen tilde?, ¿cuáles no?, ¿cuáles se escriben con be?, ¿cuáles con uve?, etc. El tipo de preguntas por plantear dependerá de las características del corpus y del grupo.

Se finaliza con la respuesta a la pregunta: ¿Por qué debemos escribir nuestro nombre de manera correcta?

2. ¿Cómo se escriben los nombres de mis amigos y familiares? (1 sesión)

Se solicita a los escolares que traigan de su casa los nombres de sus familiares y amigos, escritos en tiritas de papel del mismo tamaño, entregadas previamente por el docente.

En grupos de cuatro o cinco niños, se clasifican los nombres según los siguientes criterios:

1. Nombres que empiezan por la misma sílaba. Ej.: Maricielo, Marielos, Maribel, Mario, Matilde, etc.

2. Nombres que terminan con el mismo sonido o sílaba, según sea el caso. Ej.: Roberto, Ernesto, etc.

3. Nombres que tienen tilde. Ej.: María, Víctor, Sofía, etc.

4. Nombres escritos con "be" y "uve". Ej.: Verónica, Berta, Viviana, Víctor, etc.

5. Nombres escritos con "ese" y "ce". Ej.: Sandro, Sergio, Silvia, Sofía, Susana, Celia, Cinthya, etc.

6. Nombres que se escriben con "zeta". Ej.: Zulema, Zoraida, Zacarías, Zenén.

Se comentan los resultados de la clasificación y se llega a conclusiones generales: la importancia de escribir los nombres propios con las letras específicas de cada uno, además de hacer referencia a las consecuencias para la comprensión si se sustituye una letra por otra letra, por ejemplo: Candro por Sandro. 
3. Regularidades e irregularidades en los nombres propios (2 sesiones)

Se toman los nombres propios escritos con "ese", "ce" y "zeta", en cualquier posición dentro de la palabra y se hace un listado.

\section{Nombres con "S"}

Sandra

Sergio

Silvia

Sofía

Sonia

Susana

\section{Nombres con "C"}

Carmen

Marcelo

Maricielo

Coralia

$\cdots$

\section{Nombres con " $Z$ "}

Zeneida
Zoraida
$\ldots$
$\ldots$
$\ldots$
$\ldots$

El educador presenta el listado a los niños en un papelógrafo o cualquier tipo de cartel, se lee cada nombre y se trata de encontrar regularidades e irregularidades en la pronunciación del fonema aislado /s/, cuyos correspondientes grafemas o letras son s, c z; además debe comentarse que la letra "c" corresponde a dos fonemas distintos como en Carolina y Marcela. De tal forma que al llegar a la secuencia con la letra "ce", se concluya que esta letra seguida de las vocales "a", "o" y "u" representan el sonido "K" y las secuencias "ce" y "ci" corresponden al fonema /s/. Se repasan los nombres escritos con "ese" y con "zeta" y se llega a la conclusión de que representan el mismo sonido escrito de forma diferente, según la palabra de que se trate. También se puede concluir que son más frecuentes las palabras escritas con "ese" que con "zeta".
Recuérdese que este tipo de actividad tiene como objetivo que el escolar tome conciencia de la falta de correspondencia entre la escritura y la pronunciación de las palabras, por lo que al escribir deben considerarse los sonidos que tienen diferente tipo de escritura según la palabra de que se trate. Igualmente, debe señalarse que no existe, en la variedad de español que hablamos, razón fonética para que zapato, Zeneida, zompopa, zuampo, se escriban con "zeta", pero que deben escribirse con ese signo porque esa es su representación correcta. Por tanto, nuestro objetivo como maestros es desarrollar la conciencia ortográfica o sea el sentido de duda al escribir los fonemas que se signan con diferentes grafemas.

Las listas se podrían ampliar con nombres comunes e iniciar con los niños la elaboración de tarjetas de vocabulario.

4. Juguemos con las palabras: la "be" y la "uve" (2 sesiones)

Se sigue el procedimiento anterior, o sea se elaboran listas de palabras escritas con "be" y con "uve", con el fin de concluir que pese a que se pronuncian igual se escriben diferente.

\section{Tarjetas de vocabulario (2 sesiones)}

Se elaboran tarjetas de vocabulario a partir de los siguientes pasos:

1. Se divide el grupo en cuatro o cinco subgrupos.

2. Se entrega a cada subgrupo un número determinado de tarjetas del mismo tamaño (un promedio de cinco por niño).

3. Cada grupo debe seleccionar un promedio de veinte palabras, incluyendo nombres propios; la anotan en las tarjetas y las ilustran.

4. Cada grupo comparte las tarjetas ya terminadas.

5. Al finalizar las sesiones de trabajo, se colocan las tarjetas en un lugar determinado del aula para que sean leídas y repasadas durante diferentes momentos de la rutina diaria. 
En síntesis, con esta secuencia se inicia el trabajo con el objetivo actitudinal prioritario en el aprendizaje de la ortografía, o sea el desarrollo de conciencia ortográfica, la cual va unida a la apertura de espacios para que el alumno pregunte $\mathrm{y}$, de esta manera, desarrolle la conciencia de las posibilidades de error que existen al escribir y, poco a poco, vaya apropiándose de las fuentes y estrategias pertinentes para obtener las informaciones requeridas; en este caso la pregunta es más importante que la respuesta.

\section{Nota}

1. La negrilla es nuestra.

\section{Bibliografía}

Alarcos Llorach, Emilio. 2000. Gramática de la Lengua Española. Madrid: Espasa Calpe.

Barberá, Vicente. 1988. Cómo enseñar la ortografía a partir del vocabulario básico. Barcelona: Ceac.

Barberá, Vicente et al. 2001. Didáctica de la ortografía. Estrategias para su aplicación práctica. Barcelona: Ceac.

Camps, Anna et al. 2004. La enseñanza de la ortografía. Barcelona: Graó.

Carbonell de Grampone, María A. 2004. La ortografía. Un espacio de reflexión y desafio. Montevideo: Sociedad de dislexia del Uruguay.

Cassany, Daniel et al. 1997. Enseñar lengua. Barcelona: Graó.

Gagini, Carlos. 1897. Vocabulario de los niños. San José: Imprenta Nacional.
Gabarró Berbegal, Daniel y Conxita Puigarnau, Gracia. 1996. Nuevas estrategias para la enseñanza de la ortografía. En el marco de la Programación Neurolingüística $(P N L)$. Granada: Aljibe.

Gamboa, Emma. 1976. Evolución de la educación primaria en Costa Rica. San José: Editorial Costa Rica.

Mesanza López, Jesús. 1987. Didáctica actualizada de la Ortografía. Madrid: Santillana, Aula XXI.

Ministerio de Educación Pública. 1909. Programas oficiales. Instrucción primaria. San José: Imprenta de Costa Rica.

1926. Programas oficiales de instrucción primaria. San José: Imprenta de Costa Rica.

1936. Programas de educación primaria. San José: Imprenta de Costa Rica.

1941. Proyecto de plan de trabajo para las escuelas primarias. San José: Imprenta de Costa Rica.

1962. Plan de trabajo para las escuelas primarias. San José: Imprenta Nacional.

Ministerio de Educación Pública Nuevos programas de educación primaria (1969)

1974. Español I ciclo. San José: Departamento de publicaciones Ministerio de Educación Pública.

1977. Programa de Español, I y II ciclo. San José: Departamento de publicaciones Ministerio de Educación Pública. 
1979. Sugerencias metodológicas para un mejor desarrollo del programa de español I y II ciclo. San José: Departamento de publicaciones Ministerio de Educación Pública.

. 1987. Contenidos básicos para el I y II ciclos de la Educación General Básica. San José: Departamento de publicaciones Ministerio de Educación Pública.

. 1991. Programa de estudios. Español I y II ciclo de la Educación General Básica. San José: Departamento de publicaciones Ministerio de Educación Pública.

. 1994. Política Educativa Hacia el Siglo XXI. Recuperado el 15 de marzo de 2007, de www.mep.go.cr

1995. Programa de estudios. Español Iy II ciclo de la Educación General Básica. San José: Departamento de publicaciones Ministerio de Educación

2005. Programa de estudios. Español Iy II ciclo de la Educación General Básica. San José: Departamento de publicaciones Ministerio de Educación Pública.

Murillo Rojas, Marielos. 2004. Estudio sobre el lenguaje de los escolares costarricenses. El léxico básico. La ortografía y sus características. Tesis de doctorado no publicada, Universidad de Extremadura, España.

2005. "El verbo en la escritura cacográfica de los niños escolares costarricenses. En: Revista Campo Abierto No. 27, p.23-39.

2006. "Vocabulario cacográfico. Pautas para la enseñanza de la ortografía en la escuela primaria costarricense". En: Revista Káñina XXX (1):59-70.

Lorenzo Delgado, Manuel. 1984. El vocabulario y la ortografía de nuestros alumnos. Madrid: CINCEL - KAPELUSZ

Parera Parramon et al. 1996. "Qüestions ofertes en didáctica de la Llengua". En: MP Battaner Teresa Marbá (Eds) Barcelona: Universidad de Barcelona.

Rodríguez Sanmartín, Álvaro. 1996. La enseñanza de la ortografía en educación primaria. Madrid: Editorial Escuela Española.

Rojo, Guillermo. 2002. "Sobre la Lingüística basada en el análisis de corpus". En: Hizkuntza-corpusak. Oraina eta geroa (2002-10-24/25). Dir. electrónica: http:// www.uzei.com/modulos/usuariosFtp/ conexion/Archi63A.pdf.

Sánchez Avendaño, Carlos. 2008. “La enseñanza de la ortografía en Costa Rica: de las reglas fonodependientes a las reglas rentables y al planteamiento grafológico". En: Revista Educación, Universidad de Costa Rica. Vol. 32 (2): $97: 114$.

Salgado, Hugo. 1997. El aprendizaje ortográfico en la didáctica de la escritura. Argentina: Aique.

Vilá i Santasusana, Montserrat. 2005. " $L a$ secuencia didáctica como metodología para la enseñanza y el aprendizaje del discurso oral formal". En: M.Vilá i Santasusana (coord.):117-129. 
